\title{
POLÍTICA PÚBLICA DE PROGRESSÃO CONTINUADA, REESTRUTURAÇÃO CURRICULAR E FORMAÇÃO DE PROFESSORES: PARTICIPAÇÃO COMO POSSIBILIDADE DE AVANÇOS
}

\section{PUBLIC POLITICS OF CONTINUING PROGRESSION, CURRICULAR RESTRUCTURING AND PROFESSORS EDUCATION: PARTICIPATION WITH POSSIBILITY OF IMPROVEMENTS}

\author{
PALUDO, Conceição \\ Universidade Federal de Pelotas \\ c.paludo@terra.com.br \\ SANTOS, Magda Gisela Cruz dos \\ Universidade Federal de Pelotas \\ magdacs81@yahoo.com.br \\ TADDEI, Paulo Eduardo Dias \\ Universidade Federal de Pelotas \\ paulopiratini@bol.com.br
}

\begin{abstract}
RESUMO O texto relata e analisa o desenvolvimento de uma experiência de formação de professores realizada em uma rede municipal da Região Sul do Rio Grande do Sul. O processo formativo foi articulado à necessidade, apresentada pelos professores, de reestruturação curricular - a construção de um plano de estudos - para os três primeiros anos do Ensino Fundamental, decorrente da Resolução $n^{\circ}$ 7, de 14 de dezembro de 2010. Autores como Marx (1990; 2009), Kosik (2010), Freitas (2003), Freire (1987) e Vygotsky (2007) contribuíram na perspectiva teórico-metodológica do processo formativo. Tal processo, articulado às necessidades concretas dos professores e à sua participação no processo de estudo e de construção da proposta, foi um dos elementos centrais da metodologia e o que viabilizou, apesar da manutenção da seriação, o início da superação da fragmentação de conteúdos, pela articulação do trabalho a ser desenvolvido pelos professores em cada série e pela compreensão da lógica dialética na construção do conhecimento. Isso possibilitou, também, o avanço no entendimento da educação escolar como formação humana para a emancipação humana e da relação entre alfabetização e letramento.
\end{abstract}

PALAVRAS-CHAVE: Formação de professores. Participação. Plano de estudos. Política pública.

ABSTRACT The study describes and analyzes the development of a research in the education of professors that was performed in a network of cities, in the South area of Rio Grande do Sul (state). The education process was linked to the need presented by the professors, of curricular restructuring, the construction of a new 
study plan, during the first three years of grade school (first, second, third grade), according to resolution number 7 , approved on December $14^{\text {th }} 2010$. Authors such as Marx (1990; 2009), Kosik (2010), Freitas (2003), Freire (1987) and Vytgosky (2007) contributed in the perspective as far as theory and method in the education process. The education process, articulated to conform to the professors concrete needs and their participation in the process of study and construction of a proposal was one of the central elements in the methodology and what made it possible, in spite of the maintenance of the serial order maintenance, the beginning of overcoming the fragmentation of contents, by the articulation of the work to be developed by the professors in each grade and by the comprehension of another logic of construction of knowledge. It also created the improvement in the understanding of the school education as human development, for the human independence and to make a relationship between basic and comprehensive literacy.

KEYWORDS: Participation. Plan of studies. Public policy. Teachers' education.

\section{INTRODUÇÃO}

O presente texto pode ser caracterizado como uma reflexão a partir do desenvolvimento de um processo de formação continuada de professores, realizado durante o ano de 2012, que culminou com a reestruturação curricular e novo plano de estudos para os três primeiros anos do Ensino Fundamental de uma escola municipal da Região Sul do Rio Grande do Sul. O trabalho foi efetivado através de uma parceira entre o Projeto Observatório da Educação do Campo ${ }^{1}$, Núcleo do Rio Grande do Sul, da Universidade Federal de Pelotas/Faculdade de Educação e a Secretaria Municipal de Educação.

O referido município situa-se na região geográfica denominada "Serra do Sudeste", com área territorial de $3.651,5 \mathrm{~km}^{2}$. A população, segundo o Censo Demográfico de 2010, é de 19.841 habitantes, assim divididos por sexo: 10.108 homens e 9.733 mulheres, em sua totalidade. Na zona urbana, onde vive $58 \%$ da população, 5.569 são homens e 6.001 são mulheres, totalizando 11.570 habitantes. $\mathrm{Na}$ zona rural, o percentual populacional é de $42 \%$, sendo 4.539 homens e 3.732 mulheres, totalizando 8.271 habitantes $^{2}$.

\footnotetext{
${ }^{1}$ O Observatório da Educação é um projeto desenvolvido em rede, no qual participam também a Universidade Federal de Santa Catarina e a do Tuiuti, do Paraná.

${ }^{2}$ Disponível em: <http://www.ibge.gov.br/cidadesat/painel/painel.php?codmun=431460>. Acesso em: 27 mai. 2013.
} 
A sede do município constitui-se em uma cidade histórica, tendo por "marca" a sua participação na Revolução Farroupilha, de 1835 a 1945. A cidade ainda mantém o Centro Histórico, com um considerável acervo arquitetônico colonial e neoclássico, predominando prédios do século XIX, mas, também, com construções do final do século XVIII.

A base econômica do município é a agropecuária, a silvicultura ${ }^{3}$ e a pequena propriedade de economia familiar, principalmente nos assentamentos da reforma agrária. Na cidade, predominam o comércio e os serviços.

A rede municipal conta com treze (13) escolas, sendo três (03) de Educação Infantil, nove (09) de Ensino Fundamental e uma (01) de Ensino Fundamental e Educação Infantil, com 1.839 (mil oitocentos e trinta e nove) alunos matriculados em 2013. Dessas escolas, quatro (04) situam-se na sede do município e as demais no meio rural. Também conta com dez (10) escolas estaduais, sendo três (03) com Ensino Médio (duas no campo) e sete (07) com Ensino Fundamental (três no campo $)^{4}$. Na cidade há, também, um polo do Instituto Federal Sul-Rio-Grandense (IFSUL) e uma Associação Educacional.

A experiência de formação continuada de professores realizada partiu das necessidades postas pela Resolução $n^{\circ} 7$, de 14 de dezembro de 2010, do Conselho Nacional de Educação, que determina o fim da retenção nos três primeiros anos do Ensino Fundamental, com a implementação da Progressão Continuada. A Resolução parte do entendimento de que esse período deve ser considerado como um bloco ou ciclo ininterrupto, ampliando o tempo e as oportunidades para o avanço das crianças em seu processo de alfabetização e letramento. Complementando, a reforma do Ensino Fundamental de oito para nove anos tem como justificativa básica a necessidade de redução da evasão escolar e de ruptura com a 'cultura da reprovação, ${ }^{5}$, estendendo a todas as crianças o direito à alfabetização.

\footnotetext{
${ }^{3}$ A Secretaria Municipal de Desenvolvimento Econômico e Social denomina as florestas de Pinus, Acácia e Eucaliptos como silvicultura. Possivelmente a denominação mais precisa seria agronegócio. ${ }^{4}$ Dados obtidos junto à Secretaria Municipal de Educação.

${ }^{5}$ Prevalece a ideia de que a qualidade da educação está ligada às dificuldades na aprovação dos alunos, articulando-se com a concepção de que tais dificuldades qualificam o conhecimento. Trata-se de uma visão falsa da realidade, que encontra suas raízes no próprio processo histórico de formação socioeconômica, política e cultural do país, alicerçado, em grande medida, no discurso da competência e na concepção de igualdade formal. Na verdade, a repetência, principalmente nos anos iniciais, acaba influenciando a autoestima do aluno, desmotivando-o e fazendo com que se afaste de seu grupo, passando a conviver com colegas de menor idade, e, por consequência, aumentando a
} 
Diante das mudanças propostas pela Resolução, professores, diretores e coordenadores pedagógicos observaram a necessidade de adequação dos currículos escolares, de forma que a Progressão Continuada não passasse a constituir um problema para os estudantes nos anos seguintes de sua trajetória escolar. A 'não retenção' era interpretada pelos professores como 'passagem automática de ano' e como um 'grave problema à dinâmica do trabalho pedagógico', caso não fossem elaborados mecanismos de inclusão de todos os estudantes nas atividades de sala de aula. Os professores temiam que, na tentativa de evitar a evasão e a reprovação escolar nos anos iniciais do Ensino Fundamental, fosse provocada uma reprovação massiva, nos $4^{\circ}$ e $5^{\circ}$ anos, diante das dificuldades dos professore sem atender a estudantes em diferentes níveis de desenvolvimento e a quase inexistente estrutura para atendimento extraclasse, ou fora do espaço da sala de aula, das crianças com maiores dificuldades e/ou com deficiências acentuadas.

Assim, originou-se o convite da Secretaria de Educação do município para elaborar uma proposta de formação continuada com os professores, na qual fossem estudados os temas referentes às necessidades colocadas para o trabalho pedagógico nessa etapa do Ensino Fundamental para, a partir desses estudos iniciais e das necessidades demandadas pela realidade das escolas, reelaborar coletivamente uma proposta de currículo, chamado 'plano de estudos', para os três primeiros anos iniciais.

A proposta de formação continuada contou com aproximadamente 24 participantes em cada um dos encontros: professores dos anos iniciais do Ensino Fundamental, coordenadores pedagógicos e diretores das escolas. O trabalho dividiu-se basicamente em dois momentos, que serão descritos e analisados no decorrer do texto.

Os temas abordados nos encontros de estudos foram escolhidos a partir das necessidades de compreensão demandadas pelos professores, levantamento realizado por meio de um questionário, que serviram de referência para o estudo e reflexão em torno de questões centrais para organização curricular na perspectiva

evasão escolar. E o que mais chama a atenção é que a repetência atinge, principalmente, jovens pobres e negros, filhos das classes populares, do campo e da cidade, ou seja, o mesmo contingente humano de excluídos, explorados e oprimidos pelo modelo socioeconômico dominante. Os resultados dos censos escolares mostram, com clareza, essa realidade no Brasil. 
da emancipação humana. Por emancipação humana entende-se, de acordo com Marx (2009), que, além da política, é necessária a emancipação social, o que requer condições de reprodução digna da vida material e espiritual para o conjunto da sociedade 6 .

Os nove encontros de formação realizados foram sempre precedidos de reuniões preparatórias mensais e culminaram com a elaboração do plano de estudos para os três anos iniciais do Ensino Fundamental.

A seguir, apresentam-se algumas das principais reflexões e resultados práticos da experiência em três tópicos: o que busca explicitar o contexto do trabalho formativo realizado; o que expressa a experiência e o referencial teóricometodológico; e o que se pontua, à guisa de conclusão, como elemento de reflexão. Conclui-se que os processos formativos articulados organicamente às necessidades dos professores e que demandam a sua participação são mais trabalhosos, mas são os que efetivamente os envolvem e podem viabilizar alterações nas práticas cotidianas.

\section{A LÓGICA DAS REFORMAS DO ENSINO FUNDAMENTAL E OS DESAFIOS PARA REFLEXÃO DOS CURRÍCULOS ESCOLARES: O CONTEXTO E A PROBLEMÁTICA}

A "Resolução n 7, de 14 de dezembro de 2010 do Conselho Nacional de Educação", que implementa a Progressão Continuada e o fim da retenção nos três primeiros anos do Ensino Fundamental, tem provocado uma série de questionamentos entre os educadores no que diz respeito aos conteúdos e à avaliação escolar, conforme se pode observar no trabalho realizado com a rede municipal. Embora a referida resolução se apresente com o objetivo de qualificar os sistemas de ensino superando a "cultura de reprovação", gerou muitas angústias entre os educadores, em especial pelo seu caráter impositivo que, conforme as falas

\footnotetext{
${ }^{6}$ Toda a emancipação política é a redução do homem, por um lado, a membro da sociedade civil, a indivíduo egoísta independente; por outro lado, a cidadão, a pessoa moral. Só quando o homem individual retoma em si o cidadão abstrato e, como homem individual - na sua vida empírica, no seu trabalho individual, nas suas relações individuais -, se tornou ser genérico; só quando o homem reconheceu as suas forças próprias como forças sociais e, portanto, não separa mais de si a força social na figura da força política - [é] só então [que] está consumada a emancipação humana (MARX, 2009, p. 71-72).
} 
dos professores segue a lógica das demais reformas dos sistemas de ensino das últimas décadas: "de cima para baixo", sem considerar as necessidades das realidades locais, bem como o que têm os professores a dizer sobre as mesmas.

Em suas falas, os professores destacavam inúmeras dificuldades para lidarem com a não retenção, dentre elas a falta de condições para o atendimento de estudantes em diferentes níveis de aprendizagem em uma mesma turma, a não participação dos pais na vida escolar de seus filhos e o distanciamento entre os conhecimentos trabalhados pela escola e a realidade do campo e da cidade, enfatizando a necessidade de uma profunda revisão dos currículos escolares.

Conforme é possível observar, os limites atribuídos à política de não retenção apresentados nas falas dos professores, são relacionados não apenas à forma que a escola assume em sua totalidade, ou seja, a organização de seus tempos e espaços, conhecimento, metodologia e avaliação, mas, sobretudo, ao próprio papel social que a escola assume na sociedade de classes.

É importante destacar que a Resolução de que se fala é parte de uma ampla reforma dos sistemas de ensino, que vem ocorrendo nos últimos anos no Brasil, que, articulada às demais políticas públicas dos setores econômicos e sociais, buscam a consolidação de um cenário globalizado, nacional e internacionalmente. Krawczyk e Rosar (2001) destacam que nas últimas décadas, as políticas educacionais ganham importante destaque, pois investindo na formação de seus recursos humanos, de acordo com as necessidades de reestruturação do sistema produtivo, os estados nacionais asseguram a competitividade de seus mercados em nível internacional. Nesse sentido, cabe aos governos adequar os serviços educacionais às demandas do mercado, garantindo o que denominam "melhoria da qualidade do ensino".

É dessa maneira que surgem as chamadas "Políticas de Educação Para Todos" que, conforme destacam Shiroma, Moraes e Evangelista (2000), procuram investir em conhecimentos e habilidades específicas requeridas pela reestruturação produtiva em curso: "versatilidade, capacidade de inovação, comunicação, motivação, destrezas básicas, flexibilidade para adaptar-se a novas tarefas e habilidades como cálculo, ordenamento de prioridades e clareza na exposição", ou seja, conhecimentos e habilidades mínimas que deveriam ser construídas na 
Educação Básica, preparando para o mercado do trabalho (SHIROMA; MORAES; EVANGELISTA, 2000, p. 63).

Pela exposição das autoras, é possível observar que a escola pública para as classes populares ${ }^{7}$, desde sua expansão, a partir da Modernidade, mantém sua organização fundamentada nas necessidades do mercado de trabalho. Conforme destaca Enguita (1999), no início da Modernidade, a indústria passa a demandar um novo tipo de trabalhador, com disciplina material e hábitos adequados às novas necessidades do mercado de trabalho. A escola, apesar de não surgir com esse propósito, passou a ser um instrumento fundamental para formar o tipo de trabalhador que a indústria necessitava. A escola assume, então, o papel de doutrinamento ideológico e preparação de hábitos e habilidades necessárias ao trabalho, organizando sua estrutura nesse sentido.

Corroborando com as análises das autoras citadas, Freitas (2003) demonstra que ao longo de sua história, a estruturação da "forma escola" vem ao encontro do modelo social dominante, organizando seu tempo, espaço, conteúdos, metodologia e avaliação de acordo com a perspectiva hegemônica de cada época. No mesmo sentido, diz Marx (1990, p.83), referindo-se à educação burguesa: "E vossa educação, não é ela também determinada pela sociedade? Não é determinada pelas relações sociais nas quais educais vossos filhos, pela ingerência mais ou menos direta ou indireta da sociedade através das escolas, etc.?"

Nas últimas décadas, observa-se uma série de reformas relativas aos sistemas de ensino. Frente ao processo de reestruturação produtiva, o mercado de trabalho passa a demandar um novo tipo de trabalhador, tornando preciso um rompimento com o modelo de escola focado na disciplina e controle por parte do professor. Surge a necessidade de um modelo de escola capaz de formar sujeitos com iniciativa, autonomia, flexibilidade, autodisciplina; enfim, sujeitos capazes de se adaptarem às novas exigências do sistema produtivo. Esse novo modelo de escola, a fim de atender às necessidades da reestruturação produtiva, requer uma

\footnotetext{
${ }^{7}$ Entende-se que as classes populares são os extratos das classes trabalhadoras que economicamente possuem muitas dificuldades de reprodução digna da vida material: alimentação, abrigo, saúde; culturalmente não possuem condições de vivências e apropriação da cultura legitimada pela sociedade e requerida pela escola e, politicamente, embora votem, têm uma participação absolutamente limitada nos destinos da sociedade. A participação e influência têm maior probabilidade de acontecer quando se organizam e lutam pelos direitos, sendo expressão política de si mesmas.
} 
reorganização do tempo, espaço, conteúdo, metodologia e avaliação escolar. Entretanto, cabe observar que, embora rompendo com determinada estruturação da escola, esse modelo não rompe com a lógica pela qual está fundamentada a relação entre escola e sociedade, ou seja, não rompe com o papel socialmente demandado à escola de adaptar os sujeitos ao modelo econômico, político e cultural hegemonicamente estabelecido.

Freitas (2003, p. 14) destaca que, no discurso do Estado, a função social da escola é de oportunizar um ensino de qualidade para todos indistintamente, independente do nível socioeconômico de cada um:

Segundo essa versão, a desigualdade social deve ser compensada no interior da escola pelos recursos pedagógicos de que esta dispõe. A isso se chama 'equidade', segundo ele. Cabe à escola encontrar os meios de ensinar tudo a todos - essa é uma das funções proclamadas com muita força nos últimos anos (FREITAS, 2003, p. 14).

Dessa forma, enfatiza-se o direito de um ensino de "qualidade" para todos, desconsiderando as desiguais condições objetivas dos sujeitos e atribuindo à organização da forma escola o potencial de nivelamento social. É nesse contexto que surgem as políticas de reorganização do tempo e da avaliação escolar, na qual se insere a Resolução $n^{\circ} 7$ de 14 de dezembro de 2010 do Conselho Nacional de Educação.

Ao referirem-se às reformas relativas à reorganização do tempo e da avaliação escolar, como a Política de Ciclos ou Progressão Continuada, propostas por políticas públicas, Fortes (2006) destaca que, de modo geral, essas reformas objetivam simplesmente reverter os altos índices de reprovação/repetência e evasão escolar, tendo em vista os efeitos que apresentam para os orçamentos dos sistemas de ensino, ou seja, aderem à lógica das demais reformas de melhorar os índices de desempenho, diminuindo os custos com o sistema de ensino. Em uma perspectiva crítica e emancipatória, a autora destaca que repensar a organização do tempo e da avaliação escolar requer mais do que procurar romper com a estrutura de ensino baseada na seriação, mas, sobretudo, com a lógica de seriação que fundamenta determinado projeto de escola.

Cabe destacar que, embora não discordando da necessidade de que a escola oportunize ensino de qualidade para todos, questiona-se a possibilidade de se 
alcançar um patamar igualitário de conhecimento em uma sociedade fundamentada na desigualdade socioeconômica. Assim, observa-se que a escola, embora busque romper com a organização de seu tempo e espaço no sentido de superar a lógica seriada, apresenta limites para avançar no sentido de uma formação que contribua para a emancipação humana. Esses limites, conforme destaca Freitas (2003), estão relacionados às intensas trocas que a instituição escola estabelece com a sociedade capitalista, o que demanda uma forma de organização que, embora avance no sentido de superar a estrutura seriada, mantém seu vínculo com a lógica social hierárquica e competitiva. Nesse sentido, diz Mészáros: "A educação para além do capital visa uma ordem social qualitativamente diferente" (2008, p. 71).

Entretanto, embora considerando os limites estruturais que a escola apresenta em sua constituição em uma sociedade de classes, considera-se imprescindível de que seu currículo seja pensado no sentido de resistência aos padrões impostos pelo sistema social dominante, superando mais do que a forma de organização do tempo e do espaço, sobretudo a relação com o conhecimento, na qual os sujeitos são compreendidos apenas como parte de um sistema dado ao qual devem adaptar-se.

Foi no sentido de refletir novas formas de relação entre a sociedade e a escola, entre a escola e seus sujeitos e especialmente entre os sujeitos da escola e o conhecimento que se procurou refletir coletivamente com o grupo de professores uma proposta curricular comprometida com os interesses dos trabalhadores do campo e da cidade.

\section{A INTENCIONALIDADE DO PROCESSO FORMATIVO E O PROCESSO DE REESTRUTURAÇÃO CURRICULAR: REFERENCIAIS TEÓRICOS E PRÁTICOS}

O processo desenvolvido, considerando as preocupações dos professores, buscou refletir coletivamente sobre outra possibilidade de 'ser escola'. Nesse sentido, mais do que adequar o currículo escolar à nova organização do tempo e espaço, demandada pela Resolução $n^{\circ} 7$ de 14 de dezembro de 2010 do Conselho Nacional de Educação, procurou-se refletir com o grupo de professores sobre a 'lógica seriada' que fundamenta determinada forma da escola e as possibilidades de 
resistência que podem ser elaboradas coletivamente, a partir de outra concepção de educação, conhecimento, sujeitos, escola e sociedade.

Foi feita uma tentativa de trabalhar no sentido de confrontar a lógica hegemônica, dando absoluta importância ao envolvimento do professor no processo e a sua participação, tanto no mapeamento da 'atualidade', quanto na análise e na síntese e proposição. Considerando Marx (1990; 2009), Kosik (2010), Freitas (2003), Freire (1987) e Vygotsky (2007), orientou-se o processo formativo pelas categorias metodológicas da dialética materialista, que propõe, como elementos centrais, a historicidade, o movimento-que está na realidade-, a contradição e a totalidade ${ }^{8}$.

O esforço, conforme destacado, foi o de constatar, analisar/aprofundar, realizar nova síntese e propor junto com os professores. Ainda, tendo como referência Marx (1990; 2009), buscou-se trabalhar com a concepção de educação enquanto formação humana, o que demanda a superação da formação unilateral para uma concepção de educação omnilateral ou onilateral ${ }^{9}$, tendo como horizonte a emancipação humana.

Foi assim que, partindo das principais necessidades apontadas pelos professores, a proposta curricular foi elaborada pelo coletivo de educadores, desde a definição de seus princípios norteadores até sua finalização. A seguir, apresentase, ainda que de forma resumida, o processo.

No trabalho formativo desenvolvido, foram estabelecidos basicamente dois momentos interligados: um momento de estudos e sínteses coletivas sobre os temas de relevância, ocorrendo paralelamente à investigação da realidade; e o segundo momento, com a elaboração conjunta da proposta curricular para os anos iniciais.

No primeiro momento, foram elencados eixos de estudos e debates referentes à reforma prevista pela Resolução, o que se organizou a partir de um questionário respondido pelos professores.

\footnotetext{
${ }^{8} \mathrm{~A}$ totalidade é aqui compreendida enquanto múltiplas determinações da realidade analisada e suas mediações.

${ }^{9}$ Nos textos de Marx, encontra-se a concepção de formação integral a qual escritores de vertente marxista convencionaram chamar de omnilateral ou onilateral, conforme Manacorda (1991, p. 81). "A onilateralidade é, portanto, a chegada histórica do homem a uma totalidade de capacidades produtivas e, ao mesmo tempo, uma totalidade de capacidades de consumo e prazeres, que se deve considerar sobre todo o bojo daqueles bens espirituais, além dos materiais, e dos quais os trabalhadores tem estado excluídos, em consequência da divisão do trabalho".
} 
A dinâmica dos encontros estabelecia leituras prévias por parte de todos participantes, exposição de síntese do tema e debate coletivo, confrontando as leituras com as necessidades específicas da realidade imediata, vislumbrando o futuro. Os encontros eram sempre iniciados com a síntese do anterior e da avaliação realizada, por parte dos participantes, ao final de cada formação. Essa etapa dos estudos serviu para que, além de aprofundar a reflexão e debate sobre os temas estudados, o grupo pudesse refletir sobre as necessidades de seu contexto, as possibilidades que se apresentavam no sentido de reelaboração do currículo e os princípios norteadores teórico-práticos que deveriam acompanhar sua revisão e reelaboração, bem como a implementação no contexto escolar.

Como um dos primeiros temas, tornou-se imperativo o estudo sobre a Resolução $n^{\circ} 7$ de 14 de dezembro de 2010: o que propõe, como se justifica e quais mudanças demanda ao currículo dos anos iniciais a legislação referente ao Ensino Fundamental? A partir desse estudo, o grupo sintetizou como um dos pontos principais da legislação a possibilidade aberta, na direção de democratizar o acesso e permanência dos estudantes no contexto escolar, diminuindo os níveis de reprovação e evasão escolar, a partir da compreensão dos três anos iniciais do Ensino Fundamental como um 'bloco' dedicado prioritariamente à alfabetização e letramento das crianças de 6 a 8 anos de idade.

Diante das dificuldades destacadas pelos professores em atender a crianças em diferentes níveis de aprendizagem em uma mesma turma, o segundo encontro procurou retomar alguns conhecimentos sobre o processo de aprendizagem dos estudantes, revisitando as teorias de aprendizagem e observando as necessidades que, de modo geral, apresentam as crianças de 6 a 8 anos de idade em seu processo de aprendizagem. Esse encontro teve por objetivo refletir sobre a relação entre tempo de aprendizagem e alternativas pedagógicas para o avanço das crianças, especialmente em seu processo de alfabetização e letramento. Aqui, a síntese foi a de que esse tempo de 6 a 9 anos tem que ser visto como um tempo único, como um grande ciclo do processo de formação humana ${ }^{10}$.

\footnotetext{
${ }^{10}$ Formação é originária do latim formare, que significa, entre outras definições, na qualidade de verbo transitivo, dar forma, constituir, compor e, em sentido reflexo, educar-se, desenvolver-se. Humano, pode ser definido, em vários sentidos, como, por exemplo, a qualidade de alguém que é bondoso, compreensivo, como, também, pode fazer referência aos homens e às mulheres, ou seja,
} 
Ao refletir sobre a relação da criança com o objeto de seu conhecimento, enfatizou-se a importância do educador em oportunizar diferentes formas de interação das crianças com seu meio e os objetos de seu conhecimento, uma vez que, conforme destaca Vygotsky (2007), é na interação com o seu meio que o sujeito constrói seu conhecimento. Para Vygotsky (2007), esse meio não é apenas físico, mas cultural, social e histórico, portanto a interação do sujeito não se dá com objetos isolados, estanques, mas com um meio repleto de relações, significados e de ideologia. Nesse sentido, a aprendizagem é compreendida em uma perspectiva social e multidimensional.

Dessa forma, a partir das sínteses realizadas, tornou-se evidente que uma nova relação entre sujeito e objeto de conhecimento requer um projeto diferenciado de escola e, portanto, de currículo, o qual, traduzido no plano de estudos, diz respeito à organização da instrução, mas também da formação das crianças, o que levou a refletir a cultura da escola em sua totalidade.

Assim, na sequência dessas reflexões, observou-se a necessidade de, no terceiro encontro, debater as diferentes concepções de educação que envolvem diferentes projetos de escola e aprofundou-se o debate sobre a finalidade da educação escolar, o papel da escola do campo e da cidade e a necessidade de um projeto de escola voltado à emancipação humana.

Já no quarto encontro, procurou-se analisar as mudanças na relação entre tempo e processo de aprendizagem, proposta pela nova legislação, debatendo as diferentes perspectivas teórico-metodológicas, envolvidas na concepção da escola por ciclos e da Progressão Continuada e, ainda, as aproximações e distinções entre as referidas propostas e as diferentes concepções educacionais e projetos de escola. Com base nos estudos realizados nesse encontro, o grupo de professores pôde observar que, de modo geral, as experiências de escola por ciclos diferem radicalmente da Progressão Continuada, pois preveem mais do que a não retenção e reprovação, mas, sobretudo, estão fundamentadas em outra concepção de escola e, portanto, de currículo. 
Entretanto, ao analisar as reformas do ensino em Portugal, Argentina e na Espanha, países que instituíram a estrutura de ciclos, Fortes (2006) destaca que, embora rompendo com a estrutura seriada de escola, essas reformas aderiram a uma perspectiva liberal de educação, pois demonstram sintonia com as questões econômicas, tendo por objetivo a inserção/adaptação dos indivíduos e de seus países em uma sociedade globalizada. "Assim, observa-se que os ciclos, inseridos nessas reformas nacionais, vêm acompanhados de um currículo oficial. O caráter de expansão de tempos aos alunos choca-se com o estreitamento da possibilidade de criação dos professores e com as avaliações externas do sistema" (FORTES, 2006, p. 5). Diferentemente dessas experiências, a autora destacou duas outras realizadas em meados de 1990, nas quais a proposta da escola por ciclos estava conectada a uma atividade criadora por parte dos educadores e da comunidade escolar como um todo, o que, apesar da existência de algumas práticas unificadas em nível municipal, oportunizaram, no seu tempo, o desenvolvimento de pedagogias diferenciadas.

A partir desses comparativos, o grupo de professores percebeu que, para além da forma estrutural assumida pela escola, torna-se necessário refletir sobre a lógica pela qual orienta seu currículo, ou seja, a concepção político-pedagógica que o fundamenta.

Como culminância dessa primeira etapa do estudo, o quinto encontro constituiu-se de um relato de experiência por parte de um educador que participou da elaboração e implementação de uma escola por ciclos na região de Porto Alegre. A referida experiência está em vigor até os dias atuais e apresenta exemplos práticos de outras possibilidades de 'ser' para a escola pública, demonstrando aos professores alternativas para pensar o projeto de sua instituição.

Esse primeiro momento da formação possibilitou ao grupo dialogar sobre os limites para se ter outro projeto de escola. Alguns dos limites apontados foram: a sociedade na qual se vive, que é profundamente desigual; o papel atribuído à escola na atualidade, notadamente a pública, frente aos problemas sociais; a relação entre governo e escola, que coloca a educação a mercê dos partidos; as condições objetivas para o trabalho em contraposição ao desejo de ter tais condições; as exigências ao professore a sobrecarga de trabalho; a formação inicial dos professores que não condiz com a realidade encontrada na escola pública; os baixos 
salários e as jornadas prolongadas de trabalho; o desestímulo dos professores; as relações internas da escola, por vezes pouco solidárias; a forma como a inclusão foi proposta e implementada nas escolas e as condições para a realização efetiva da mesma. Foram debatidas também as possibilidades de superação dos mesmos, além de sintetizar os princípios norteadores para a nova proposta curricular.

Durante o sexto encontro, que constituiu um momento de avaliação sobre a primeira etapa da formação, os professores consideraram possível a elaboração de uma proposta curricular que, embora não estruturada a partir dos ciclos, procurasse levar em consideração uma outra forma de 'ser escola' e os princípios teóricometodológicos sintetizados pelo grupo.

A partir dos estudos e reflexões realizadas, esses princípios acompanharam todo o processo de elaboração da proposta curricular, sendo revisitados a cada etapa de elaboração, como 'filtro' e critério de avaliação das propostas apresentadas. Os mesmos foram resumidos da seguinte forma: a) partir sempre da realidade, das experiências de vida e das representações dos sujeitos; b) analisar criticamente os temas abordados, desdobrando-os em subtemas e articulando-os com os conteúdos escolares, ampliando os níveis de conhecimento; c) trabalhar com a totalidade do sujeito oportunizando uma formação intelectual, corporal e emocional $^{11}$; d) trabalhar sempre do concreto para o abstrato, partindo do mais próximo e ampliando níveis de compreensão; e) considerar que todos podem aprender - cada um tem o seu ritmo, cabe ao educador propor as mediações para o avanço dos estudantes.

Um desses princípios, partir da própria realidade dos sujeitos e da representação que possuem dela, demandou um conhecimento para além daquele possível ao primeiro olhar dos professores e impulsionou a etapa seguinte da elaboração da proposta: a realização de uma investigação sobre a realidade de cada comunidade escolar. Dessa forma, os professores foram instigados a construir um diagnóstico a partir do olhar que apresentam sobre a realidade na qual atuam,

\footnotetext{
${ }^{11}$ A relação trabalho-educação não foi possível de ser desenvolvida. A opção do grupo que coordenou o processo formativo foi a de avançar na formulação, na medida do avanço na compreensão e elaboração pelos professores. A proposta era a de seguir acompanhando o grupo, quando da implementação da proposta em 2014. Nesse processo haveria a continuidade do estudo, da reflexão e das proposições práticas.
} 
descrevendo suas impressões, limites, necessidades e as possibilidades que observavam para aquele contexto.

Paralelamente, a partir de eixos temáticos amplos, elaborou-se um questionário semiestruturado para ser aplicado pelos professores junto aos estudantes de cada escola, o qual contava com eixos investigativos sobre a rotina, vivências marcantes, opiniões e interesses das crianças em seu contexto doméstico, comunitário e escolar.

O questionário foi aplicado pelos professores com todos os estudantes do $1^{\circ}$ ao $3^{\circ}$ ano do Ensino Fundamental, compreendendo um período de um mês e meio para a coleta desses dados. Após a coleta dos dados, organizou-se uma comissão com pelo menos um professor representante de cada escola para a organização e leitura dos dados que orientariam a delimitação coletiva dos principais eixos temáticos que apareceram nas falas dos estudantes.

No encontro coletivo, então, os professores, divididos em grupos de aproximadamente dez componentes, foram instigados a selecionarem, a partir dos dados da investigação, as principais situações daquele contexto que poderiam ser codificadas em eixos temáticos ou temas geradores, conforme denominava Freire (1987).

Sobre o tema, destaca esse autor:

É na realidade mediatizadora, na consciência que dela tenhamos educadores e povo, que iremos buscar o conteúdo programático da educação. O momento deste buscar é o que inaugura o diálogo da educação como prática da liberdade. É o momento em que se realiza a investigação do que chamamos universo temático do povo ou o conjunto de seus temas geradores. Esta investigação implica, necessariamente, numa metodologia que não pode contradizer a dialogicidade da educação libertadora. Daí que seja igualmente dialógica. Daí que, conscientizado-a também, proporcione, ao mesmo tempo, a apreensão dos temas geradores e a tomada de consciência dos indivíduos em torno dos mesmos. [...] o que se pretende investigar, realmente, não são os homens, como se fossem peças anatômicas, mas o seu pensamento-linguagem referido à realidade, os níveis de sua percepção desta realidade, a sua visão de mundo, em que se encontra, envolvidos seus temas geradores. (FREIRE, 1987, p. 50)

De acordo com esse entendimento, a busca pelos eixos temáticos ou temas geradores implica uma reflexão crítica sobre as relações homem-mundo, homenshomens, procurando compreender o tema gerador em sua pluralidade, em sua constituição histórica. Com efeito, na nossa mediação procurou-se assim proceder, 
provocando junto aos professores reflexões quanto à relevância de cada tema e os desdobramentos possíveis que apresentava.

Segundo Freire (1987, p. 57), a investigação temática exige um processo de busca e criação a partir do qual os sujeitos vão descobrindo a interpenetração dos problemas, "[...] assim é que, no processo de busca da temática significativa, já deve estar presente a preocupação pela problematização dos próprios temas, por sua vinculação com outros" (idem).

Desse modo, as codificações são objetos cognoscíveis que representam uma situação existencial, portanto, "devem ser simples na sua complexidade e oferecer possibilidades plurais de análises na sua descodificação, [...] são desafios sobre que deve incidir a reflexão crítica dos sujeitos descodificadores" (FREIRE, 1987, p. 62). Nesse sentido, a partir das situações investigadas e dos temas codificados, procurou-se analisar com os professores os "temas dobradiças" (FREIRE, 1987) ou, conforme denominou-se, subtemas, que possivelmente viessem a emergir no processo de descodificação junto aos estudantes. É a partir dos temas dobradiças ou subtemas que se torna possível realizar a redução temática, ou seja, cindir um tema em suas parcialidades, núcleos fundamentais, para, a partir da reflexão crítica das partes, voltar ao todo com maior clareza.

Com base no debate coletivo com o grupo de professores, chegou-se ao seguinte esquema, como proposta inicial, para a organização curricular ${ }^{12}$ :

Figura 1. Organização curricular.
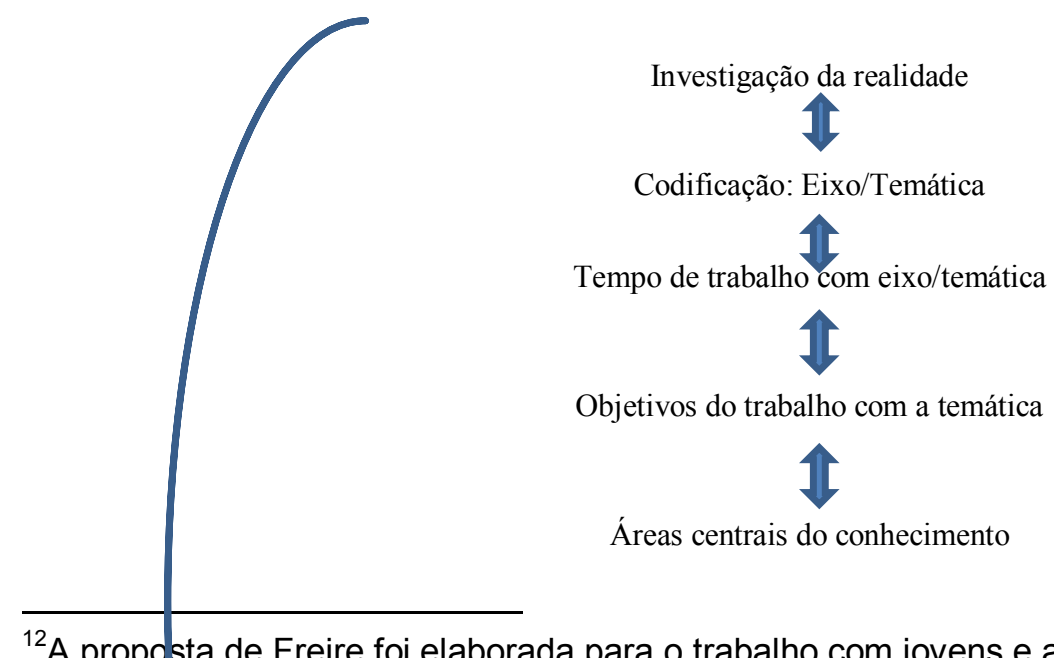

${ }^{12}$ A proposta de Freire foi elaborada para o trabalho com jovens e adultos. Na experiência ho curso de Pedagogia da Universidade Federal de Pelotas, em estágios com educação de jovens e adultos, há quatro anos está se realizando um trabalho nessa mesma perspectiva. Nessa situação específica, o desafio fci o de pensar as adequações e inovações necessárias, para os três primeirbs anos do Ensino Fundamental, tendo como estudantes as crianças. 


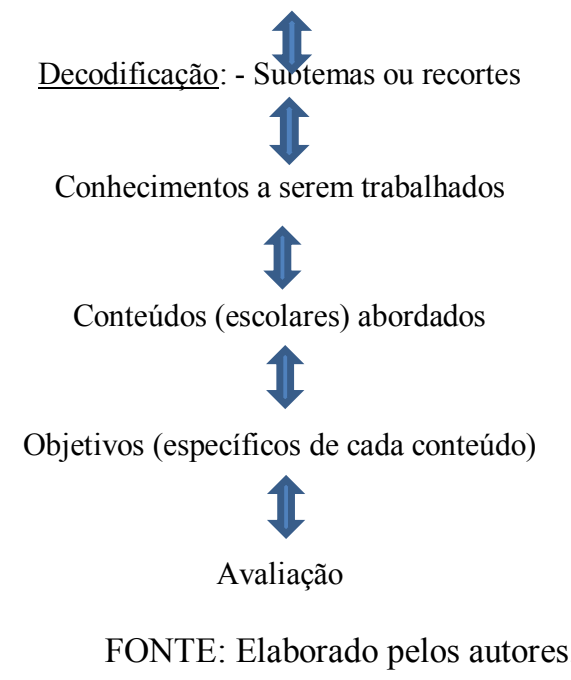

Com base nessa dinâmica e na pesquisa realizada junto aos estudantes, os professores foram instigados a analisara interconexão dos temas, bem como suas possíveis graduações para os diferentes anos e a relação dos mesmos com os conhecimentos escolares.

Durante o processo de elaboração da proposta, os professores demonstravam uma grande preocupação em relação aos conteúdos escolares e questionavam sobre a possibilidade de articulação dos temas abordados com os conhecimentos trabalhados pela escola. Havia uma preocupação por parte dos professores em não "se abrir mão dos conteúdos escolares". Em relação a essa preocupação, procuramos enfatizar ao longo dos estudos e da elaboração prática da proposta que um projeto de escola que parta da realidade imediata dos estudantes, tendo por perspectiva a emancipação humana, não pode de forma alguma "abrir mão" dos conhecimentos historicamente acumulados pela humanidade $\mathrm{e}$ trabalhados pela escola, mas, ao contrário, pressupõe uma nova relação entre esses conhecimentos, os sujeitos e sua realidade.

A partir da análise crítica das dimensões significativas de sua realidade propostas como temas, os educandos e educadores voltam com mais clareza à totalidade analisada. Nesse sentido, os temas representam a codificação de uma situação contextual. Já a descodificação representa a análise crítica da situação codificada. 
existencial provoca esta postura normal, que implica num partir abstratamente até o concreto; que implica numa ida das partes ao todo e numa volta desta às partes, que implica um reconhecimento do sujeito no objeto (a situação existencial concreta) e do objeto como situação em que está o sujeito (FREIRE, 1987, p. 55).

Dessa forma, a proposta curricular elaborada para os três anos iniciais do Ensino Fundamental, partindo de temas do contexto dos estudantes e das escolas participantes, procurou desdobrá-los em subtemáticas que, articuladas aos conteúdos escolares e conhecimentos trabalhados pela escola, procuram ampliar a cada etapa o nível de compreensão crítica, tanto dos estudantes quanto dos educadores sobre essa realidade, seu potencial de elaborar ações no sentido de superar os limites colocados por essa realidade, assim como propiciar aos estudantes o processo de alfabetização articulada ao letramento.

\section{PONDERAÇÕES SOBRE O PROCESSO}

Como toda proposta de mudança, a Resolução $n^{\circ} 7$ de 14 de dezembro de 2010 do Conselho Nacional de Educação provocou a insegurança entre os professores da rede pública, diante das mudanças que propõe e da falta de esclarecimento em relação aos objetivos, e certa ambiguidade nas justificativas. De certa forma, observa-se que as preocupações apresentadas pelos professores, em relação à referida Reforma, são problemáticas presentes na realidade escolar, mesmo antes da proposta, como, por exemplo, a dificuldade em atender estudantes em diferentes níveis de aprendizagem em uma mesma turma.

O que se observa é que a Reforma provocou o debate em torno de questões já latentes na realidade escolar e, no caso da experiência apresentada, em torno da questão do projeto de escola que se tem e do projeto de escola apropriado para a realidade dos trabalhadores do campo e da cidade, na perspectiva da emancipação humana.

Observamos que esse não é um debate que se esgota em apenas um ano de formação continuada com os educadores, pois requer uma profunda revisão nas concepções que envolvem as práticas dos educadores de escolas públicas que atendem às classes trabalhadoras. 
No primeiro momento, percebeu-se uma forte resistência dos professores em relação ao objeto da formação continuada pela indignação frente às modificações no Ensino Fundamental e, sobretudo, pela forma como se processaram essas modificações, principalmente no que concerne a não retenção nos três primeiros anos. No início, em suas avaliações individuais, os professores manifestavam contrariedade no tocante às discussões teóricas propostas, dando a entender que gostariam de trabalhar a prática, de preferência com "modelos prontos".

A posição da maioria dos professores, no primeiro momento, mostrou-se contraditória, pois, se por um lado eles refutavam a forma como foi estabelecida a reforma do Ensino Fundamental (de cima para baixo, sem discussão com os protagonistas do processo), por outro não demonstravam interesse em construir uma nova proposta a partir dessa exigência legal, esperando algo pronto, de cima para baixo da Secretaria Municipal de Educação ou mesmo do Observatório da Educação do Campo. Com efeito, paradoxalmente, os professores estavam renunciando o protagonismo na construção da nova proposta para o Ensino Fundamental no município.

Todavia, com o aprofundamento das discussões, eles começaram a entender que estava nas mãos deles e delas a construção de uma nova proposta para a não retenção nos primeiros três primeiros anos das séries iniciais. A partir dessa compreensão e também do entendimento da indispensabilidade da articulação entre a teoria e a prática para a construção e implantação da nova proposta, as resistências foram arrefecendo, dando lugar a uma maior participação por parte da maioria como protagonistas do processo de construção da mesma ${ }^{13}$.

Registre-se também que um pequeno grupo manteve a resistência até o final do processo, não por não aceitar a coordenação do Observatório e da Secretaria Municipal da Educação, mas por não acreditar que esta acataria a proposta construída coletivamente pelos professores, o que, no final, aconteceu, pois houve outra opção e o encerramento da formação, no momento em que estava sendo

\footnotetext{
${ }^{13} \mathrm{Um}$ dos elementos que comprova o que se escreveu foi o fato de oitenta por cento dos professores comparecerem ao último encontro de formação do ano, realizado já no período em que estavam em férias, 19 de dezembro de 2012. Isso não estava previsto, mas foi necessário para a conclusão da proposta. Eles queriam iniciar o ano de 2013 já com a mesma em condições para iniciar a implementação.
} 
iniciada a implementação da proposta e a elaboração do processo avaliativo da mesma, já no ano de 2013.

Todavia, observa-se que a partir da experiência realizada teve inicio uma de ampla e aprofundada reflexão sobre o projeto de escola da rede municipal nessa realidade. No entanto, diante da nova conjuntura política do município e da Secretaria de Educação, o Observatório da Educação do Campo não acompanhou a implementação da proposta. Essa dificuldade talvez tenha se colocado frente à percepção, por parte da Secretaria, do caráter de ruptura da proposta elaborada, com o projeto de escola proposto pela política do governo municipal. Outro aspecto que pode ter interferido para a continuidade do trabalho que vinha sendo realizado pode ter sido a troca da pessoa responsável, pelo mesmo, na secretaria. Observouse que a pessoa que assumiu a responsabilidade não estava informada de modo adequado. De qualquer maneira, a experiência vivenciada coloca a necessidade de maior esforço de pesquisa no que diz respeito às relações entre governos e redes municipais, assim como a política pública e as redes de ensino, que ocorrem nos espaços locais. Tudo indica que nessas relações, prevalecerá decisão do poder público, sempre em detrimento da escola, e de seus sujeitos.

Finalmente, nessa experiência, mais uma vez constatou-se que o processo formativo, articulado às necessidades concretas dos professores e a sua participação no estudo e na construção da proposta, foi um dos elementos centrais da metodologia e o que viabilizou o envolvimento dos professores. Apesar da manutenção da seriação, o início da superação da fragmentação de conteúdos, pela articulação do trabalho a ser desenvolvido pelos professores em cada série e pela compreensão de outra lógica de construção do conhecimento e da necessidade do trabalho coletivo, levou a avanços na formulação. Além disso, viabilizou o avanço no entendimento da educação escolar como formação humana para a emancipação humana e a relação entre alfabetização e letramento.

\section{CONCEIÇÃO PALUDO}

Doutora em Educação pela Universidade Federal do Rio Grande do Sul (UFRGS). Docente e pesquisadora da UFPel, na Faculdade de Educação - Departamento de Fundamentos da Educação e da Linha de Pesquisa Filosofia e História da Educação. 


\section{MAGDA GISELA CRUZ DOS SANTOS}

Mestre em Educação pela Universidade Federal de Pelotas (UFPel). Professora da rede pública estadual e municipal de Pelotas/RS.

\section{PAULO EDUARDO DIAS TADDEI}

Mestre em Educação pela Universidade Federal de Pelotas (UFPel). Advogado. Graduando em Filosofia no Claretiano Centro Universitário. Professor especial convidado do Curso de Pós-Graduação "lato sensu" da Faculdade Porto das Águas (Porto Belo, SC).

\section{REFERÊNCIAS}

ENGUITA, M. F.A face oculta da escola: educação e trabalho no capitalismo. Trad. Tomás Tadeu da Silva. Porto Alegre: Artes Médicas, 1999.

FORTES, G. H. M. Escola por Ciclos e Políticas Educacionais. In: PETRY, O. J.; ALMEIDA, R. H. C.; SANTOS, J. A, S. (Org.). O estado brasileiro contemporâneo e o reordenamento das políticas públicas. Macapá: 2006, p. 143-170.

FREIRE, P. Pedagogia do Oprimido. 17. ed. Rio de Janeiro: Paz e Terra, 1987.

FREITAS, L. C. de. Ciclos, seriação e avaliação: confronto de lógicas. São Paulo: Moderna, 2003.

KOSIK, K. Dialética do concreto. Trad. Célia Neves e Alderico Toríbio. Rio de Janeiro: Paz e Terra, 2010.

KRAWCZYK, N.; ROSAR, M. de F. Diferenças de homogeneidade: elementos para o estudo da política educacional na América Latina. Dossiê Políticas Educacionais. Educação e Sociedade. Campinas, CEDES, ano XXI, n. 75, ago. 2001.

MANACORDA, Mario Alighiero. Marx e a pedagogia moderna. São Paulo: Cortez: Autores Associados, 1991.

MARX, K. Sobre a questão judaica. São Paulo: Expressão Popular, 2009.

MARX, K.; ENGELS, F. Manifesto do Partido Comunista. 3. ed. Petrópolis: Editora Vozes Ltda., 1990.

MÉSZÁROS, I. A educação para além do capital. 2. ed. São Paulo: Boitempo, 2008.

SHIROMA, E. O.; MORAES, M. C. M. de; EVANGELISTA, O. Política Educacional. Rio de Janeiro: DP\&A, 2000. 
Atos de Pesquisa em Educação - ISSN 1809-0354

Blumenau, v. 9, n.3, p.720-741, set./dez. 2014

DOI: http://dx.doi.org/10.7867/1809-0354.2014v9n3p720-741

VYGOTSKY,L.S. Formação social da mente. Martins Fontes. São Paulo. 2007. 